\title{
AUGMENTED TURIN BAROQUE ATRIA: AR EXPERIENCES FOR ENHANCING CULTURAL HERITAGE
}

\author{
V. Palma ${ }^{1}$, R. Spallone ${ }^{2}$, M. Vitali ${ }^{2}$ \\ ${ }^{1}$ FULL, Politecnico di Torino, Torino, Italy, valerio.palma@polito.it \\ ${ }^{2}$ Department of Architecture and Design, Politecnico di Torino, Italy, (roberta.spallone, marco.vitali)@polito.it
}

\section{Commission II}

KEY WORDS: Augmented Reality, Cultural Heritage, 3D Modelling, Open Source, Baroque Atria

\begin{abstract}
:
This paper presents the most recent developments in a project aimed to the documentation, storage and dissemination of the cultural heritage. The subject of the project are more than 70 Baroque atria in Turin, recognized by critics for their particular unitary vaulted systems Our research team is currently working on digitizing documents and studying ways to enhance and share these results through ICT. In particular, we want to explore possibilities for recognizing and tracing three-dimensional objects in augmented reality (AR) applications connected to the collected data. Recent developments in this field relate to the technology available on widespread mobile devices such as tablets and smartphones, allowing for real-time 3D scanning. Using software prototypes, we want to introduce some problems involved in integrating this technology into digital archives.
\end{abstract}

\section{INTRODUCTION}

Turin Baroque atria, characterized by complex vaulted systems, are a unique case in the architecture of the time. These atria have been realized with particular spatial schemes that present: unified spaces, absence of intermediate pillars, and composite vaults made of brickwork masonry. Three main types of vaulted systems established: the "star-shaped" vaults, the "Planterian" vaults, and the "a fascioni" vaults. It is a Cultural Heritage of great interest but it is little known and visited by the public, especially if intended as an urban system.

The authors of this proposal recognized over 70 atria linkable to these features (Spallone and Vitali, 2017).

Baroque architects internationally known, as Guarini, Juvarra and Vittone, and others, less famous, but very important for the development and the diffusion of these kind of atria, as Garove, Baroncelli and Plantery, designed some of them.

Among other critics, Norberg-Schulz evidenced the interest of these spaces, in his book on Late Baroque Architecture, in which Turin's atria are widely described (Norberg-Schulz, 1980).

Moreover, we catalogued them identifying:

- their location inside the walls of the baroque city

- their relationships with the palaces and the urban tissue they belong to

- their main dimensions

- the geometries that shape the vaulted system

- the bibliographical and archival references

We also deepened the knowledge about the most paradigmatic examples through surveys, 2D drawings and interpretative 3D models (Figg. 1-2).

At the same time we started to imagine some thematic routes in the city center useful to explain and share their discoveries to the citizens and tourists.

Using the tools offered by the digital revolution we are today working in the direction of an enhancement, valorisation and sharing of this heritage, mixing and merging real and virtual documentary materials and fruition experiences.

Indeed, the desire and the will to communicate share and spread the values of this heritage and the results of the investigations carried out, were the motivations for undertaking two different and complementary actions, currently under development.
On the one hand, the collection is being inserted into a website dedicated to the communication and dissemination of Cultural Heritage Tourism; on the other, AR applications are being experimented, in order to allow, during on-site visits, to display short descriptions, iconographic documents, bibliographic references, geometric models of the vaults, and survey drawings, as well as to connect to the web portal for further deepening. We believe that these two tools have to be considered for their synergistic potentials, so their features have to be accurately set. Moreover, we would like to involve users more effectively, tracing their paths and asking them to share their experiences. They will then be able to make their personal itineraries, comments, suggestions, photographs, etc. available for other visitors.

As a corollary of the proposal, there is the objective of exploiting open source software and low-cost display devices, normally available to users.

In the present proposal, we will deepen the reasoning about AR experiments, at the center of today phase of our research.

\subsection{Challenges in AR research}

In the '90s several formal definition and classification for augmented reality were stated (i. e. Milgram, Takemura et al., 1994).

From the beginning of the application of AR in various fields of technology, production and knowledge some issue related to the relationships between real and virtual emerged.

They were well summarized by Bimber and Raskar, who observed: "The fact is that in contrast to traditional VR, in AR the real environment is not completely suppressed; instead it plays a dominant role. Rather than immersing a person into a completely synthetic world, AR attempts to embed synthetic supplements into the real environment (or into a live video of the real environment). This leads to a fundamental problem: a real environment is much more difficult to control than a completely synthetic one" (Bimber and Raskar, 2005).

The most important challenges in AR research, in those days like at present, are tracking and registration, display technology and rendering that represent its fundamental components. 

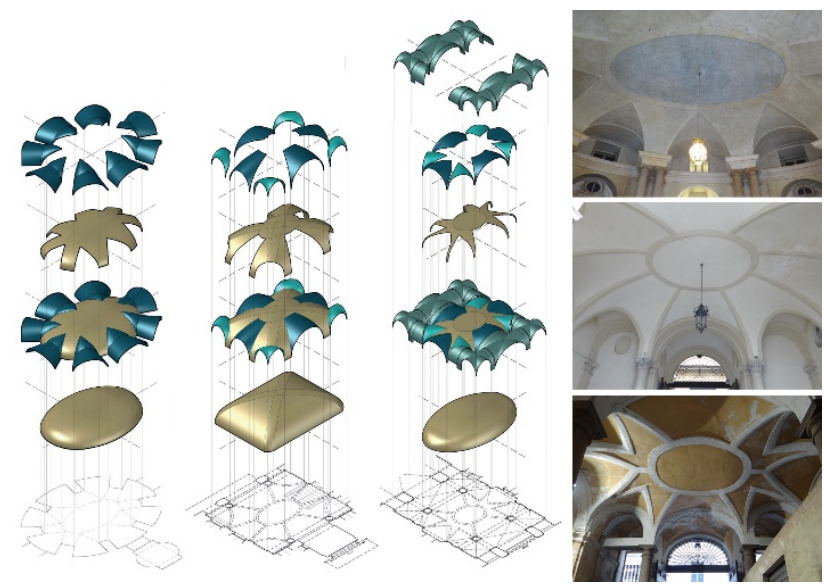

Figure 1: Interpretative 3D models of the lunette's dome of Palazzo Carignano and the Planterian vaults of Palazzo Cigliano and Novarina

\section{RELATED WORKS}

\subsection{AR experiences by superimposition of 3D digital} models and real buildings

Case studies that use markerless methodology aimed to the superimpositions of 3D reconstructive models to built cultural heritage are not numerous. Among the most recent case studies, and similar to the present experience in regard to the features of the historic buildings, there are those on the Roman Theatre of Byblos and on the plaster cast of the portal of Saint-Pierre Church in Moissac, preserved at the Musée des Monuments Français (MNF) in Paris. The first realized an outdoor experience, the second an indoor one.

The first case was developed by a research group from the American University of Beirut (Younes et al., 2017).

This case study presents a lot of similarities with the issues of our research.

The Theatre of Byblos is today in a ruin condition and poor state of conservation that makes very difficult to appreciate its function and value as a cultural heritage to the visitors.

The philological reconstruction of the existent Roman Theatre started from the survey of the archaeological remains through SfM (Structure from Motion) technology.

Then, the comparison between the surveyed remains and the Vitruvian models of Greek and Roman theatres allowed to hypothesised that the shape, as a variant of the Roman scheme, has been generated by five triangles rotated each other of $24^{\circ}$. Moreover, the comparison with the Odeon at Aphrodisias and the Theatre of Aspendus suggested other elements for modelling the features of Byblos theatre.

Augmented reality technology in this case shows its potentiality extending and enriching in real-time the information that the visitors could draw observing the ruins. The seamless integration between the virtual models and the actual scene is one the result of this application. To do this, differently from our case, the model has been mapped and photo-realistically rendered. Moreover, the environment was accurately reconstructed, adjoining green, sky, sea, and lighting conditions. Another difference is in the way of fruition of the AR application. Indeed, due to the desire to produce an immersive experience and to the frequent bright sunlit conditions of the site, it was preferred a completely immersive headsets, such as the Oculus Rift.

As in the words of the scholars, the most interesting challenges of this case study that can be shared with our research are:

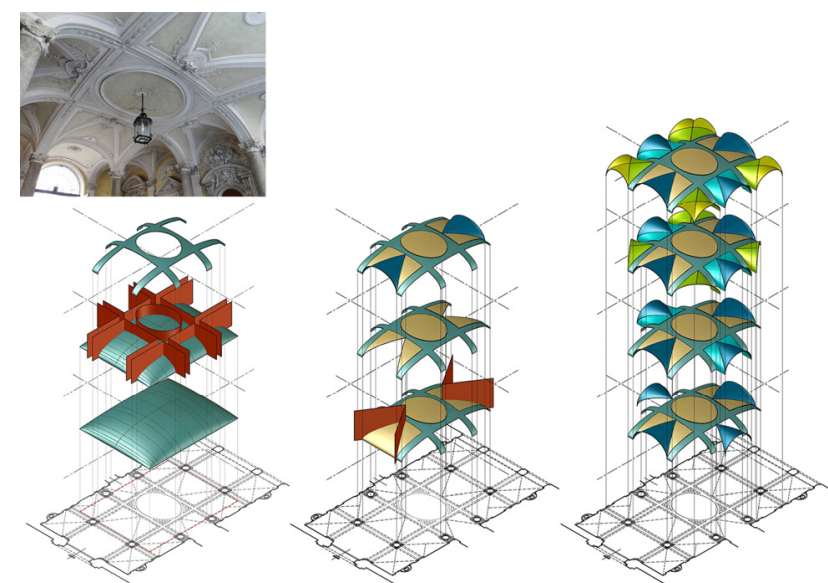

Figure 2: Interpretative 3D models of the "a fascioni" vault of Palazzo Coardi

the interaction with the augmented cultural heritage model while the user is off-site which holds tremendous power in drawing users and potential tourists to explore the site and plan their visits and tours accordingly;

the development of site models that allow a user to navigate through the site to explore its various features, and can engage the user by adding information to an otherwise passive experience (Younes et al., 2017).

The second case was carried out by a research group from IUAV in Venice (Cannella and Gay, 2018).

In this case the plaster cast of the church portal of Moissac is located inside a museum. So, the matter is to reproduce, indoor, the geometric features of the monument giving the visitors the idea to enter in the real building.

Nevertheless, in this case, the model has been synthesised by simple geometric volumes and has been only clay-rendered. This choice that we share in our research, allows distinguishing in a more effective way the real and the virtual, and appreciating the geometric shape of the indoor recomposed building.

Another feature of the project, shared in our work, is the possibility by the users of setting the grade of transparencies for visualizing together the portal and the model, choosing on what the attention has to be focused.

Also the visualizing tools are the same. Indeed, in the Museum is foreseen the use of tablets and smart-phones that involves the fruition of personal devices, avoids to meet obstacles along the way, and creates a perceptive distance between real and virtual useful to the fruition of the real architecture.

If the acquisition technologies and the AR experiences are similar, compared to the case studies examined, in our project the significance of the superimposed model changes. In fact, it is not a reconstruction of a disappeared reality aimed to a morphological and realistic representation, nor a reconstruction of an architecture by dislocation, but an interpretation of the geometry underlying the ideation of the space, of which animations are planned to demonstrate possible compositions and re-compositions (even alternatives) and to display representations with a high abstraction content, such as plans and sections.

\subsection{AR experiences aimed to enhance Cultural Tourism}

It seems important and proper to refer to two of the most recent research that take stock of issues related to the use of AR in researches specifically related to the enhancement of Cultural Heritage, including through tourism experiences.

In our opinion both research are a valid methodological reference to achieve, through more strictly technical issues, that 
we refer to the following sections of this paper, results and applications that favor and support guided tourist experiences through the implementation of itineraries and visiting routes, linked the application of the AR on specific elements of a widespread heritage that provides anchorage mechanisms that do not rely on the use of markers.

The first work, conducted by a research group coordinated by Hoshang Kolivand (Kolivand et al., 2018) constitutes a census, conducted exhaustively, on the main objectives and characteristics of AR marker-less technologies through the presentation of the most advanced results in this specific field of application. In parallel to the technical application issues are developed arguments on the cultural content of the application of the AR for the visualization of Cultural Heritage, both to assist scholars in their research and to communicate cultural heritage in education and in tourist experiences, also showing interesting and encouraging data on the results of research in the field that saw the administration of questionnaires on usability and user satisfaction.

The most interesting results for this work come from the application of AR to support the tourist experience of cultural heritage sites, which bases on the real-time visualization of computer-generated virtual content (models, drawings and documents) on mobile devices such as smartphones and tablet. The research is based on the state-of-the-art related to marker-less $\mathrm{AR}$ such as indoor marker-less AR, outdoor marker-less AR, real-time solutions to the tracking problem, real-time registration. The work systematizes the main issues and challenges and some of the latest trends in the search for simple and accessible solutions without the use of too advanced tools, such as the development of new marker-less systems that uses local features-based image registration and structure from motion (SfM) technology (Sato et al.,2016).

Finally, the research reports in tabular form a full comparison of different techniques for marker-less augmented reality on the main researches analyzed.

The second work taken in analysis constitutes a specific experience of the application of the AR for the construction of one complete mobile tourist guide for the enhancement of cultural heritage sites located in the old town of Chania, Crete, Greece (Panou et al., 2018).

Parallel to the construction of a visit path, in fact, augmented reality experiences are implemented with markerless technology in which the immersive experience is granted by the overlap, on mobile devices, of 3D models of historical buildings in their past state onto the real world, while users visit the Venetian part of Chania's city, associating with the three-dimensional view information in the form of text and images. The experiment was conducted through the construction of a specific route around the Venetian part of the city thinking to the path that a tourist holding a mobile phone would traverse, implementing the AR experience on three significant monuments, in an attempt to promote the public appreciation of cultural heritage sites and showcase the cultural depth of the city. The experience appears particularly interesting for the opportunity to interact with historical monuments in non-intrusive ways, thus eliminating the need to interfere with the remains and on-going archaeological research.

The development of the research is described in all its salient passages and broadly describes the visit experience and the use of the specific app by the end user. In relation to the AR visualization, the selected monuments are virtually restored in order to enable visitors to see them integrated into their real environment. The aim is to associate $3 \mathrm{D}$ visualizations to geolocated information to the users, through text, images, and help visitors to document their visits.

Furthermore, the AR mobile application developed is aimed to provide for future additions of digital content, and requires a moderate amount of development and technical expertise.
Also in this case we really appreciate the ex-post evaluation of the research by informal tests and questionnaires on usability and visiting experience, which allow us to highlight fully achieved results, critical issues and elements that could be improved, particularly linked to geolocation, the superimposition of three-dimensional models to reality.

One aspect that we consider particularly important is that linked to the possibility for users to give feedback on their visit experience and to share information and experiences with other users.

\subsection{Space and databases for cultural heritage}

The amount of data and documents related to architectural and cultural heritage has increased over recent decades and has raised issues of accessibility of the collected information.

Digital tools for surveying and processing architectural data have detailed the representations and multiplied the levels of analysis.

In order to keep together quantitative and qualitative approaches and different file formats and analyses, it is not enough to hierarchically organize contents: a more complex topology of information is needed. Therefore, much work has been done in the cultural and archaeological heritage fields to give a rich semantic structure to databases and contents. This work builds on the broad research stream on metadata interoperability (Kakali et al., 2007; Eide et al., 2008) and refers to the infrastructures of the Semantic Web (Sure and Studer, 2005; Berners-Lee et al., 2001).

Spatial and temporal attributes have gained a key role in architectural heritage, connecting information though shared schemes, and contributing to advancements in the information management technologies (Saygi and Remondino, 2013).

Geographic information systems (GIS) have long been used to cope with heritage-related and archaeology-related issues. These systems have proven effective in storing, editing and managing spatial information on sites and artworks, and have been used on both 2D and 3D data - and we can even talk of 4D for the temporal representations (Soler et al., 2017; Cerutti et al., 2015; Apollonio et al., 2012).

Subsequently, the use of more appropriate tools to manage 3D models has grown, thanks to technological developments in capturing and processing this kind of data (Auer et al., 2014). The need for enabling the interaction of the models with a database has brought to exploit the properties of the building information modelling (BIM). This set of tools has evolved following the needs of the architectural and engineering industry, but it shows positive results also when implemented in existing buildings, with advantages in translating the survey data (e.g. laser scanning data) into semantic information, and in managing and updating the stored data.

Volk et al. (2014) present an extensive literature review on the use of BIM for existing buildings.

The search of the best solutions to manage spatial information also concerns the detailed exploration of the differences between BIM and GIS (Saygi and Remondino, 2013; Saygi et al. 2013). The integration of the two semantic approaches through different mapping and information exchange techniques is also addressed by a broader field than heritage (Liu et al. 2017, Song et al., 2017; Hor et al., 2016).

The challenges for information integration and interoperability also concern access to information through visualization, dissemination and usage. These actions should not necessarily be related to the knowledge of modelling and programming software or to GIS, BIM or database management skills. Indeed, many studies produced web-based archives, using flexible languages like SQL to make data available for different kinds of 
users across multiple platforms (Auer et al., 2014; Scianna et al., 2013).

Among the projects working on contents interoperability to enable dissemination and multimedia applications, an example is Arches, a management system for the heritage field developed by the Getty Conservation Institute and World Monuments Fund (Arches Project, 2018; Myers et al., 2016). The Arches software is free and open source, it is based on international standards and it is currently implemented into different projects for heritage documentation. Arches is compatible with desktop GIS applications, it features web visualization and management functions and it is preparing mobile apps to access the archives.

Another example is INCEPTION, an ongoing international project aiming to build a digital description framework for the European cultural heritage (INCEPTION Project, 2018; Maietti et al., 2018). The project addresses the production and management of enriched 3D representations by adopting shared semantic schemes. A data platform to collect the information is under development, which will allow for information visualization and management through web services and mobile software.

Our group is collaborating with the researchers from the University of Padua who worked on the Cult platform (Cult project, 2018), a system used to test the sharing of information between a database and websites, tourist apps and BIM and GIS models.

\subsection{Development of AR technologies for a widespread use}

Information accessibility in a digital archive via mobile devices can now benefit of the potential of these widespread interfaces. One of the opportunities is to make the exploration of a digital model more similar to the experience of a real space, using systems such as virtual reality (VR) and augmented reality (AR).

AR applications allow to superimpose a digital informative layer to images of the perceived world in real time (Amin and Govilkar, 2015).

AR technologies have had a great commercial success in virtual entertainment, a leading sector for technological advancement in realtime computer graphics (Anderson et al., 2010). Many AR applications in cultural heritage are possible, as has been pointed out since the late 90s (Brogni et al., 1999), for AR is an effective and intuitive medium to explore the digital models made available by advanced surveying and modelling tools.

Augmentation can for instance reveal inaccessible places, no longer existing structures or virtual anastylosis, and it can enable user's interaction with the surrounding space and with field-related information.

AR applications can now be shown on single-camera devices, such as smartphones and tablets, but more immersive technologies can be implemented, such as goggles and other headsets. Developers in this field face many opportunities, as shown in reviews of AR software by Fraga-Lamas et al. (2018) and by Amin and Govilkar (2015).

A key feature of AR technologies is the accurate estimation of the observer's position. This is needed to reconstruct the relative position and the perspective view of the virtual images, in order to give the illusion of a position in the real world. The estimation of the point of view can be achieved through different techniques, including visual pose tracking techniques (Younes et al., 2016; Yang et al., 2013) and techniques based on data from other sensors such as inertial platforms.

Those approaches blending computer visual techniques and information from sensors can get a stable and realistic augmentation also on the more common devices on the market. This solution is currently marketed by major companies in the
IT sector, including Google and Apple with their ARCore and ARKit AR software.

Another feature of these systems is the need to process the real space to understand where to place (in a virtual space) the digital models. Among the available solutions, modeled based tracking and markerless tracking are recently appearing. These allow to anchor the virtual content with no need for twodimensional markers, a common means to locate a planar surface and a reference system origin (Amin and Govilkar, 2015). Such opportunities may open new ways to connect real world and digital models.

\section{DEVELOPED METHODOLOGY}

\subsection{About the choice of the case studies}

The selected case studies present particular value as cultural heritage and features that make them eligible for the application of AR technology.

From the cultural point of view, they represent: the archetype of star-shaped vault (Palazzo Carignano), the first step of shape elaboration of Planterian vaults (Palazzo Novarina and Palazzo Cigliano), and one of the most interesting example of "a fascioni" vault (Palazzo Coardi).

From the point of view of the applicability of AR experiments, they are accessible, have different sizes and ratios between width, depth, and height, and have a good condition of lightening (natural and artificial).

The vault of Palazzo Carignano (Guarino Guarini 1679), supported by eight coupled columns, is a lowered ovoid dome cut by planes and completed by eight groins with triangular plans. The columns, spaced from the outside walls, create an

ambulatory covered by little barrel vaults that are separated by the architraves connecting to the walls.

The atrium of Palazzo Novarina (Gian Giacomo Plantery first decade of 17 th C.) has a main vault cut by planes with a triangular projection, and it is completed by longitudinal, transverse, and angular groins. This vault is bordered by two colonnaded diaphragms with groin-vaulted aisles.

The atrium of Palazzo Cigliano (Plantery 1707-08) has the main cloister vault cut by radial planes. Along the two axes, there are groins of completion and there are little sail vaults in the angles.

The atrium of Palazzo Coardi (Amedeo di Castellamonte undated) has a central atrium preceded and followed by two diaphragms and bordered by columns and covered by a central sail and two lateral groin vaults. The central space is defined by eight free columns that hold up an "a conca" vault in which the cuts along the longitudinal and transversal axis generate areas covered by groins surfaces, while the rectangular corner cuts are filled by portions of sail and half-groin vaults.

\subsection{Storage tools}

The choice of a tool to store data and digital document depends on the project goals. The main needs are:

- $\quad$ to provide contents which are suitable both for specialist and non-specialist users;

- $\quad$ to record the many different outputs of the documentation phases of the research, hence to manage different file formats;

- $\quad$ to improve the accessibility of digital information through multiple software, devices and media.

The storage platform should therefore be interoperable, should enable the integration of data and offer a multi-level accessibility. 

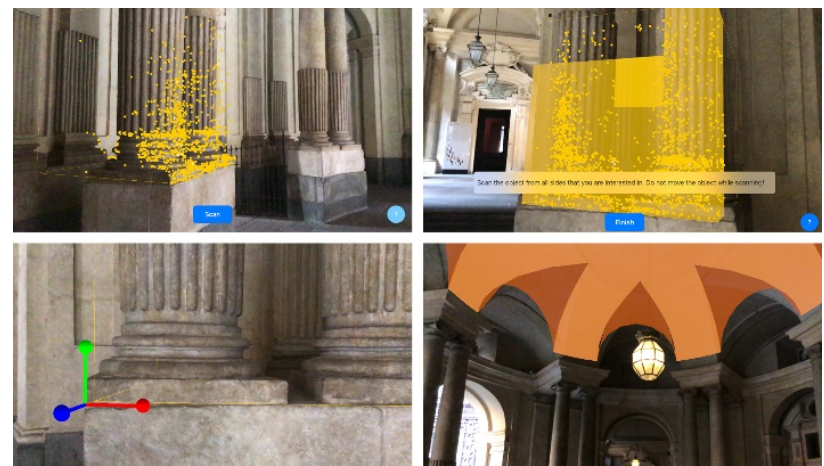

Figure 3: The scanning procedure in Palazzo Carignano: (1) definition of the bounding box; (2) scanning of features of the target object; (3) positioning of the origin of the reference system; (4) superimposition in the visualization app of the interpretative models to the real vaults.

The ongoing project have already been collaborating with the University of Padova to improve the Cult web service (Palma et al., 2018). Cult is an experimental toolkit to manage and disseminate theoutputs of researches on the cultural and architectural heritage (Cecchini et al., 2019; Bortot et al., 2017). At present, this service makes it possible to store documents and metadata, to connect them to georeferenced features and to retrieve the information through desktop, web and mobile apps.

The system is based on open standards and only uses free and open source software (FOSS). The metadata scheme used is based on the Dublin Core Metadata Initiative standard (DCMI, 2018, Haus, 2016; Kakali et al., 2007), though some limitations are introduced due to the development status and the choices for the simplification of the web interface.

The research team is working on the digitalization of the archive on the baroque atria, uploading a database entry for each atrium intended as physical object and linked entries for its representations (images, models) and its related documents (such as archive sources).

The database will offer interactive access options through different connected apps. We want thereby to test the platform and plan updates and integrations to support multimedia applications including AR.

\subsection{Augmented reality tools}

Through AR, we intend to make the digital works produced by the research group viewable on-site. In particular, we decided to visualize as augmentation the geometrical interpretation of the vaults, choosing four atria as an initial sample in order to understand the opportunities and the challenges.

For this experimental phase, we choose to employ low-cost technologies. This choice is connected to both having dissemination as one the goals and the fact that commercial success is one of the main drivers of today's development of graphics related technologies - as also suggested by the closure of the Tango project by Google, in favor of ARCore, which has lower hardware requirements (Luigini and Panciroli, 2018).

Software development kits (SDK) like Vuforia, Wikitude and ARKit were evaluated. These offer free tools for the development phases and they feature real-time 3D object recognition and tracking. Furthermore, they are supported by many environments for app programming, including Unity, which is one of the most advanced and widespread cross-platform game engines. These kits are also cited in recent literature on AR applications (Blanco-Novoa, 2018; Fraga-Lamas 2018; Luigini and Panciroli, 2018; Amin and Govilkar, 2015), even if 3D object tracking functions are still little addressed.
Vuforia and Wikitude are feature-rich commercial products. Vuforia introduced object recognition functions based on CAD models, while Wikitude uses videos and pictures to get information on the target object. Tests on these tools will be conducted in further developments of the research, for an in-depth study for the input data is necessary evaluating both point clouds at different densities and geometric reconstructions in the case of Vuforia and referring to existing studies on simultaneous location and mapping (SLAM) techniques in the case of Wikitude.

For the experiments we have conducted so far, the SDK ARKit by Apple has been chosen. The SDK includes libraries to scan real-world objects and get a target model for recognition and tracking. These functions were implemented in a scanner app based on a sample software by Apple. The scanning procedure works through the following steps: (1) a bounding box is defined while superimposed on the camera image, which is an AR application itself; (2) the key features of the objects inside the box are collected moving around the box in a guided procedure; (3)the reference system origin is manually moved in the desired position, again through the AR view; (4) the produced model can be tested and exported in an ARKit-specific file format (Fig. 3).

A second app enables AR visualization. The target model and the model for the final visualization are uploaded in this app and matched.

Other software discussed in the literature shows limits in respect of the project needs. As an example, the free and open source software artoolkitX does not currently implement object recognition. Another case is Google's ARCore, which is capable of environmental understanding but does not seem to allow tracking of specific 3D objects.

\section{EXPERIMENTS}

The tests were conducted using a 6th generation iPad tablet. The chosen sites showed different conditions as of space dimensions, architectural forms, types of decoration and lighting conditions.

The scanner app uses a bounding box to limit the area in which key points are captured. The best results were achieved using less than two meters wide boxes. In the smaller atria we succeeded in scanning column capitals and part of the vault decoration (Fig. 4).

These cases made possible to have the reference object near the position of the augmentation, because del digital models represent the vaults from the spring-line up. Palazzo Carignano presented a different situation. Due to the height of the vault (keystone of 9.25 $\mathrm{m}$ ), the scanner app could not recognize enough points to generate a model, so the base of two coupled columns was used as reference object.

Larger bounding boxes were also tested (Fig. 5). As shown in the image of a 7 meters wide cubic box defined in the atrium of Palazzo Carignano, only the parts that could be framed from close up resulted in a dense point cloud. Other problems in choosing a larger space to scan in such structures are related to the fact that most of the features that can be useful for recognition (such as decorations and relief elements) are in the upper and usually less enlightened part of the atrium space. Furthermore, smaller bounding boxes resulted in more stable models already during the scanning phases, and they more often led to valid reference models.

One of the problems connected to the creation of a reference model with ARKit is defining the correct location for the superimposed models. In the scanner app, the camera interface is used to manually choose the orientation and position of the axes, making it difficult to accurately place the reference system origin. This is because the recognition files used by the SDK to store the real-world object 



Figure 4: From left column: Palazzo Novarina, Palazzo Coardi, Palazzo Cigliano. The upper images represent the anchoring objects (bounding box around target object).

information are not compatible with any software for 3D visualization. Hence, it is impossible to define the relative position of the real and digital objects, outside from the AR interface.

Indeed, the position of the virtual model at the time of tracking namely the relationship between model and scanned object - has been corrected with two different techniques. The first one is made available by the scanning app, and consists in loading a model (in .usdz format) that can be moved and scaled together with the origin. As a second technique, we manually adjusted the position of the superimposed model directly in the final AR visualization app, using a set of editable parameters. This issue still reproduces the limits of the two-dimensional markers, which do not allow the use of too large models.

The use of smaller a bounding box achieved better results in terms of origin position accuracy, though not being as much effective for the correct rotation of the whole model of the vault. Conversely, a larger box has been useful for the axis rotation - because the reference axes are by default oriented as the faces of the box - but the position of the origin can be more difficult to determine if the augmentation is not stable or if the detected subject cannot be observed from several sides.

We think that the use of a non-local reference system might be a development with a view to generalizing the use of these technologies in the field of spatial digital archives. E.g., the reference system could be computed on the basis of a GIS connected both to the reference model and the visualization model.

A digital archive can also solve the problem of the disk space occupied by models. In this case, we only used very simple and lightweight models for the visualization part. However, each of the smaller objects scanned (less than two meters wide) produced files of 2 to over $10 \mathrm{MB}$. This is a strong limitation on the scalability of the system if a web infrastructure and a good connection are not implemented.

With the use of Cult, we intend to make this kind of development possible. 

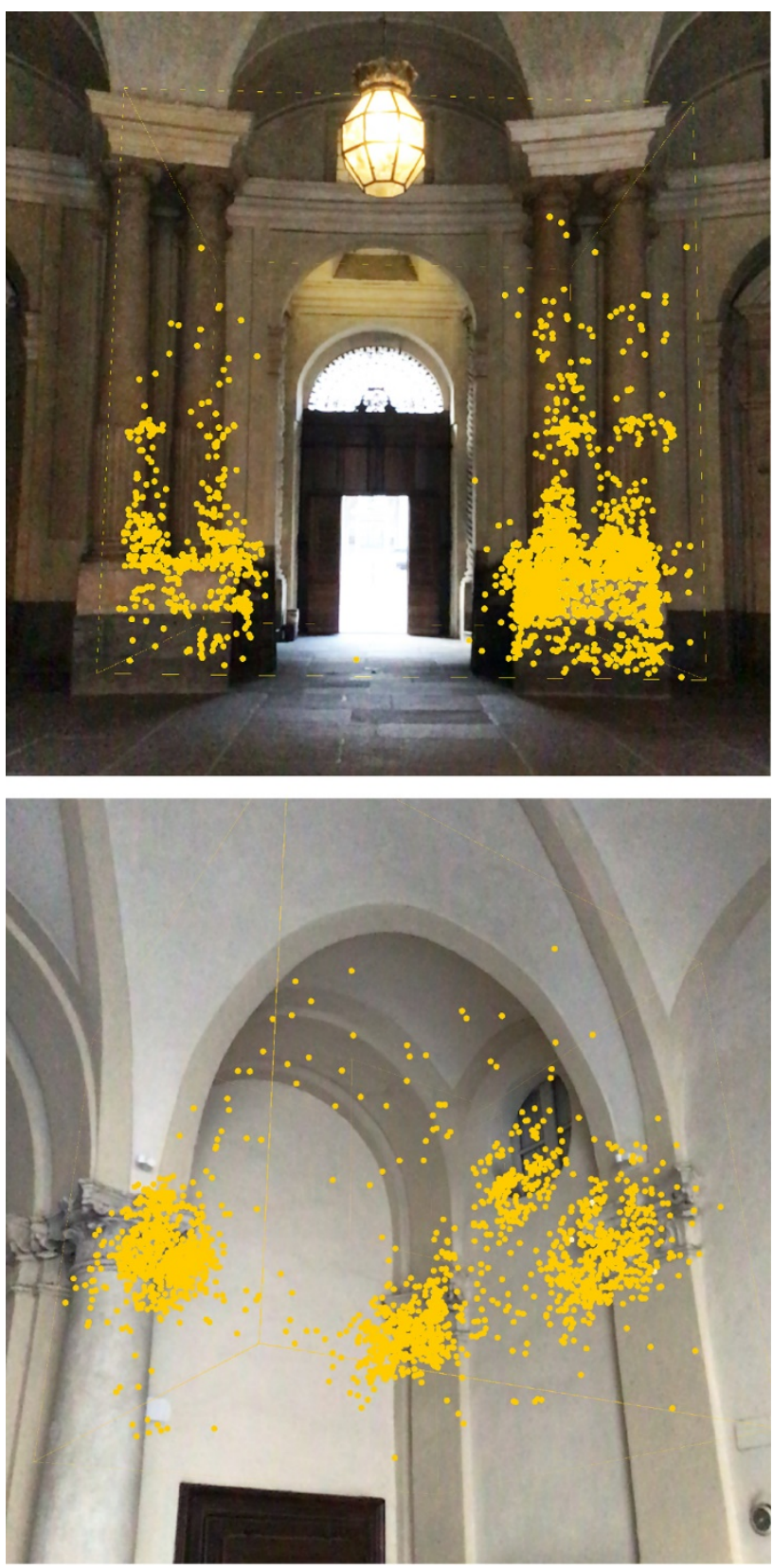

Figure 5: Screenshot of the scanner app: test of the larger bounding boxes for the scanning of target objects in the atria of Palazzo Carignano and Palazzo Cigliano

At present, the Cult platform allows users to view a digital map of the atria via web and to use it to explore the collection. In addition, Cult uses a web API to share data in machine readable formats. As discussed, these functions predispose interactions with mobile devices and these can be extended to AR apps in order to link the real space with other representations such as floor plans and sections, integrate dynamic and parametric views and access other information and documents about the details or the context.

\section{CONCLUSIONS}

This study intends to focus attention on AR applications exploiting three-dimensional object recognition, a yet not widely discussed application in cultural heritage literature.
Some crucial developments of the project aim at joining the AR functions and the work on digital archives conducted by the research team.

A more detailed comparative study on the available SDKs is certainly needed. Furthermore, systems based on free and open source software should be a way to go to optimize the interoperability and sustainability of the project, even if a greater effort could be required for software development. The goal is to identify which technologies involve more interoperable components and which offer scalable solutions.

Meanwhile, technical solutions, functionalities, tools and software compatibility are quickly changing. Attention must therefore be paid to the continuous transformations of the technological landscape enabling AR solutions.

This paper is the result of a research project carried out from the authors during the last year. Valerio Palma wrote paragraphs 2.3, 2.4, 3.2, 3.3 and 4. Roberta Spallone wrote paragraphs 1.1, 2.1 and 3.1. Marco Vitali wrote paragraph 2.2. Introduction and Conclusions were written together by Valerio Palma, Roberta Spallone, Marco Vitali.

\section{REFERENCES}

Amin, D. and Govilkar, S., 2015. Comparative Study of Augmented Reality SDK's. International Journal on Computational Science \& Applications, 5, pp. 11-26.

Anderson, E.F., McLoughlin, L., Liarokapis, F., Peters, C., Petridis, P. and de Freitas, S., 2010. Developing serious games for cultural heritage: a state-of-the-art review. Virtual Reality, 14, pp. 255-275.

Apollonio, F.I., Gaiani, M. and Benedetti, B., 2012. 3D reality-based artefact models for the management of archaeological sites using 3D GIS: a framework starting from the case study of the Pompeii Archaeological area. Journal of Archaeological Science, 39, pp. 1271-1287.

Arches project, 2018. https://www.archesproject.org (Last accessed on 1 December 2018).

Auer, M., Agugiaro, G., Billen, N., Loos, L. and Zipf, A., 2014. Webbased Visualization and Query of semantically segmented multiresolution 3D Models in the Field of Cultural Heritage. ISPRS Annals of Photogrammetry, Remote Sensing and Spatial Information Sciences, II-5, pp. 33-39.

Berners-Lee, T., Hendler, J. and Lassila, O., 2001. The Semantic Web. Scientific American, 284, pp. 34-43.

Bimber, O. and Raskar, R., 2005. Spatial Augmented Reality. Merging Real and Virtual Worlds. A K Peters.

Blanco-Novoa, O., Fernandez-Carames, T.M., Fraga-Lamas, P. and Vilar-Montesinos, M.A., 2018. A Practical Evaluation of Commercial Industrial Augmented Reality Systems in an Industry 4.0 Shipyard. IEEE Access, 6, pp. 8201-8218.

Bortot, A., Boscaro, C., Cecchini, C., Francesca, C., Cundari, M.R., Palma, V., Panarotto, F. and Siviero, L., 2017. TU-CULT. Rivelazioni architettoniche nelle chiese di Santa Giustina e di Santa Maria dei Servi a Padova. In: Territori e frontiere della rappresentazione/Territories and frontiers of representation. $39^{\circ}$ Convegno internazionale dei docenti e delle discipline della rappresentazione. Gangemi Editore, pp. 911-920.

Brogni, A., Avizzano, C., Evangelista, C. and Bergamasco, M., 1999. Technological approach for cultural heritage: augmented reality. In: RO-MAN'99: Proceedings of the 8th IEEE International Workshop on Robot and Human Interaction, pp. 206-212.

Cannella, M. and Gay, F., 2018. Ambienti aumentati e archeologia dei media. In: Luigini, A. and Panciroli, C. (eds.), Ambienti digitali per l'educazione all'arte e al patrimonio. Franco Angeli, pp. 64-78. 
Cecchini, C., Cundari, M.R., Palma, V. and Panarotto, F., 2019. Data, Models and Visualization: Connected Tools to Enhance the Fruition of the Architectural Heritage in the City of Padova. In: Marcos, C.L. (ed.), Graphic Imprints. International Congress of Graphic Design in Architecture, EGA. Springer International Publishing, pp. 633-646.

Cerutti, E., Noardo, F. and Spanò, A., 2015. Architectural Heritage Semantic Data Managing and Sharing in GIS. In: Proceedings of the 1st International Conference on Geographical Information Systems Theory, Applications and Management. SCITEPRESS - Science and Technology Publications, pp. 121-128.

Cult project, 2018. http://cult.dicea.unipd.it (Last accessed on 1 December 2018).

DCMI, 2018. http://dublincore.org/ (Last accessed on 1 December 2018).

Eide, O., Felicetti, A., Ore C., E., D'Andrea, A. and Holmen, J., 2008. Encoding Cultural Heritage Information for the Semantic WEB. Procedures for Data Integration through CIDOC-CRM Mapping. In: Proceedings EPOCH Conference on Open Digital Cultural Heritage Systems, ARCHAEOLINGUA.

Fraga-Lamas, P., Fernández-Caramés, T.M., Blanco-Novoa, Ó. and Vilar-Montesinos, M.A., 2018. A Review on Industrial Augmented Reality Systems for the Industry 4.0 Shipyard. IEEE Access, 6, pp. 13358-13375.

Haus, G., 2016. Cultural Heritage and ICT: State of the Art and Perspectives. DigitCult | Scientific Journal on Digital Cultures, pp. 920.

Hor, A.-H., Jadidi, A. and Sohn, G., 2016. BIM-GIS Integrated Geospatial Information Model Using Semantic Web And RDF Graphs. ISPRS Annals of Photogrammetry, Remote Sensing and Spatial Information Sciences, III-4, pp. 73-79.

INCEPTION project, 2018. https://www.inception-project.eu (Last accessed on 1 December 2018).

Kakali, C., Lourdi, I., Stasinopoulou, T., Bountouri, L., Papatheodorou, C., Doerr, M. and Gergatsoulis, M., 2007. Integrating Dublin Core metadata for cultural heritage collections using ontologies. In: Proceedings of International Conference on Dublin Core and Metadata Applications, e-LIS.

Kolivand, H., El Rhalibi A., Abdulazeez S. and Praiwattana P., 2018. Cultural Heritage in Marker-Less Augmented Reality: A Survey. In: Turcanu-Carutiu, D. (ed.), Advanced Methods and New Materials for Cultural Heritage Preservation. Intechopen.

Liu, X., Wang, X., Wright, G., Cheng, J., Li, X. and Liu, R., 2017. A State-of-the-Art Review on the Integration of Building Information Modeling (BIM) and Geographic Information System (GIS). ISPRS International Journal of Geo-Information, 6(53).

Luigini, A. and Panciroli, C. (eds.), 2018. Ambienti digitali per l'educazione all'arte e al patrimonio. Franco Angeli.

Maietti, F., Di Giulio, R., Piaia, E., Medici, M. and Ferrari, F., 2018. Enhancing Heritage fruition through 3D semantic modelling and digital tools: the INCEPTION project. IOP Conference Series: Materials Science and Engineering, 364.

Milgram, P., Takemura, H., Utsumi, A. and Kishino, F., 1994. Augmented Reality: A Class of Displays on the Reality-Virtuality Continuum. In: Proceedings of SPIE: Telemanipulator and Telepresence Technologies 2351, pp. 282-292.

Myers, D., Dalgity, A. and Avramides, I., 2016. The Arches heritage inventory and management system: a platform for the heritage field. Journal of Cultural Heritage Management and Sustainable Development, 6, pp. 213-224.

Norberg-Schulz, C., 1980. Architettura Tardobarocca. Electa.

Panou, C., Ragia, L., Dimelli, D. and Mania, K., 2018. An Architecture for Mobile Outdoors Augmented Reality for Cultural
Heritage. ISPRS International Journal of Geo-Information, 7(463), pp. 1-24.

Palma, V., Lo Turco, M., Spallone, R. and Vitali, Marco, 2018. Augmented Iconography. AR applications to the fortified Turin in the Theatrum Sabaudiae. In: Marotta, A. and Spallone, R. (eds.), Defensive Architecture of the Mediterranean, Vol. IX, pp. 1053-1060.

Sato, Y., Fukuda, T., Yabuki, N., Michikawa, T. and Motamedi, A., 2016. A markerless augmented reality system using image processing techniques for architecture and urban environment. In: Living Systems and Micro-Utopias: Towards Continuous Designing. Proceedings of the 21st International Conference on Computer-Aided Architectural Design Research in Asia (CAADRIA 2016), pp. 713-722.

Saygi, G., Agugiaro, G., Hamamcıoğlu-Turan, M. and Remondino, F., 2013. Evaluation of GIS and BIM Roles for the Information Management of Historical Buildings. ISPRS Annals of Photogrammetry, Remote Sensing and Spatial Information Sciences, II-5/W1, pp. 283-288.

Saygi, G. and Remondino, F., 2013. Management of Architectural Heritage Information in BIM and GIS: State-of-the-Art and Future Perspectives. International Journal of Heritage in the Digital Era, 2, pp. 695-713.

Scianna, A., Gristina, S., and Sciortino, R. (2013). Integrazione di sistemi GIS FOSS e modelli dati 3D PDF per la fruizione multimediale di beni monumentali e archeologici: il Castello di Maredolce a Palermo. In: Stanco, F., and Gallo G. (eds). Free, libre and open source software e open format nei processi di ricerca archeologica. Eight edn. Archaeopress.

Soler, F., Melero, F.J. and Luzón, M.V., 2017. A complete 3D information system for cultural heritage documentation. Journal of Cultural Heritage, 23, pp. 49-57.

Song, Y., Wang, X., Tan, Y., Wu, P., Sutrisna, M., Cheng, J. and Hampson, K., 2017. Trends and Opportunities of BIM-GIS Integration in the Architecture, Engineering and Construction Industry: A Review from a Spatio-Temporal Statistical Perspective. ISPRS International Journal of Geo-Information, 6, 397.

Spallone, R. and Vitali, M., 2017. Star-shaped and Planterian Vaults in Turin Baroque Atria. Aracne.

Sure, Y., Studer, R., 2005. Semantic Web technologies for digital libraries. Library Management, 26, pp. 190-195.

Volk, R., Stengel, J. and Schultmann, F., 2014. Building Information Modeling (BIM) for existing buildings — Literature review and future needs. Automation in Construction, 38, pp. 109-127.

Yang, M.-D., Chao, C.-F., Huang, K.-S., Lu, L.-Y. and Chen, Y.-P., 2013. Image-based 3D scene reconstruction and exploration in augmented reality. Automation in Construction, 33, pp. 48-60.

Younes, G., Asmar, D., Elhajj, I. and Al-Harithy, H., 2016. Pose tracking for augmented reality applications in outdoor archaeological sites. Journal of Electronic Imaging, 26.

Younes, G., Kahil, R., Jallad, M., Asmar, D., Elhajj, I., Turkiyyah, G. and Al-Harithy, H., 2017. Virtual and augmented reality for rich interaction with cultural heritage sites: A case study from the Roman Theater at Byblos. Digital Applications in Archaeology and Cultural Heritage, Vol. 5, pp. 1-9. 